\title{
A Survey on the Risk Factors Analysis and Evaluation for the types of VDT Work
}

\author{
Day Sung Kim \\ Occupational Safety and Health Research Institute, KOSHA, Incheon, 403-711
}

\begin{abstract}
Objective: The purpose of this study was to analyze the risk factors of MSDs for the types of office work. Background: Physical risk factors of VDT(Video Display Terminal) associated with shoulder and neck musculoskeletal disorders(MSDs) include static work postures and workstation status. Method: In this study, office work was divided into data search, data entry and design work(drawings, etc.), and then we were surveyed 7 major work places which was included these works. We recorded working postures and obtained still images, depending on the types of office work. Then, RULA(Rapid Upper Limb Assessment) and ROSA(Rapid Office Strain Assessment) were used to analysis the risk factors. Results: The results of RULA showed that design work was under risk levels and required change, but ROSA showed that data entry and design work were high risk. The RULA is to evaluate the level of risk factors based on the working posture; on the other hand, the ROSA is to consider the use of peripheral, same as chair, keyboard/mouse, monitor and computer workstations. Conclusion: Conclusions of this study, the office work is necessary to identify the risk factors caused by the use of peripheral, as well as working posture.
\end{abstract}

Keywords: VDT, Musculoskeletal disorders, Office work environment, RULA, ROSA

\section{Introduction}

오피스작업(Office work)은 국제표준화기구(International Organization for Standardization; 이하 ISO) 9241-2에 정의되어 있는데, 종래의 사무실에서 공장의 설계실이나 대 학의 연구실 등에서 주로 수행하던 정신적인 작업을 수행 하는 것을 의미한다(KS A ISO 9241-2, 2007). 오피스작 업 중에서 특히 컴퓨터를 이용하는 작업을 영상표시단말기 (Visual Display Terminal; 이하 VDT) 사용작업이라 하는 데, 적절한 우리말이 없어 $\mathrm{VDT}$ 사무작업이라는 용어가 일 반적으로 통용된다.

VDT 사무작업은 VDT 워크스테이션(VDT Workstation,
사무용 주변기기)을 포함하고 있는데, 키보드(Keyboard), 마우스(Mouse), 표시화면(Monitor), 컴퓨터 본체(Central Processing Unit, $\mathrm{CPU}$ ), 작업대 및 의자 등으로 구성되어 있다. 이러한 VDT 사무작업은 은행, 일반사무, 설계, 정밀 검사 등에서 주로 수행되어 왔으며, 최근에는 홈쇼핑, 증권 및 카드회사, 통신회사 등의 콜센터 상담업무의 증가, 컴퓨 터 게임, 프로그램 개발업무 등 새로운 형태의 VDT 사무작 업이 발생하고 있다. 또한, 인터넷환경의 구축과 개인 컴퓨 터의 보급으로 사무직 종사자뿐 아니라 학생 및 일반 사용자 들에게까지 확산됨으로 인해, VDT 작업환경은 이제 모든 인 구영역에 상당한 영향을 미치고 있다.

$\mathrm{EU}$ 에서는 컴퓨터를 이용하여 업무를 수행하는 사람이 전 체 작업자의 $52 \%$ 에 해당하며(ErgoFound, 2011), 미국의

Corresponding Author: Day Sung Kim. Occupational Safety and Health Research Institute, KOSHA, Incheon, 403-711.

Phone: +82-32-510-0838, E-mail: ergoman@kosha.net

Copyright@2013 by Ergonomics Society of Korea(pISSN:1229-1684 eISSN:2093-8462). All right reserved.

(c) This is an open-access article distributed under the terms of the Creative Commons Attribution Non-Commercial License(http://creativecommons.org/licenses/by-nc/3.0/), which permits unrestricted non-commercial use, distribution, and reproduction in any medium, provided the original work is properly cited. http://www.esk.or.kr 
경우, 2001년에는 53.3\%였던 것이 점점 증가하여, 2009년 도 인구센서스 조사결과, $68.4 \%$ 에 해당하는 것으로 조사되 었다. 연령별로는 18 34세가 79.9\%로 가장 높았고, 35 44 세가 $78.5 \%, 45 \sim 64$ 세가 $72.5 \%, 3 \sim 17$ 세가 $61.6 \%$ 순으 로 나타났다(U.S. Census Bureau, 2011).

우리나라의 경우, 2011년말 종사자수 1 인 이상 사업체 335 만여 개를 대상으로 VDT 작업환경에 대해 조사한 결 과, 사업체의 $61.4 \%$ 가 컴퓨터를 보유하고 있으며 보유사업 체 중 $90.1 \%$ 가 데스크탑을 사용하며, 노트북(넷북 포함)은 $17.5 \%$ 로 나타났다. 직원의 평균 컴퓨터 이용률은 일주일에 적어도 한 번 이상 컴퓨터를 이용하여 업무를 수행하는 비율 이 전체 $82.9 \%$ 이며, 업무상 인터넷 이용률이 $80 \%$ 이상인 사업체가 $72.8 \%$ 로 나타났다(NIA, 2012). 사업장이 아닌 가정 (가구) 의 경우를 살펴보면, 가구 내 컴퓨터 보유 비율은 $82.3 \%$ 이며, 이 중 $82.1 \%$ 가 인터넷 접속이 가능하고, $63.7 \%$ 가 스마트기기를 보유하고 있으며 20대가 91\%, 30대가 $87.5 \%, 40$ 대가 $72.3 \%$ 로 20 40대의 스마트기기 보유율이 전체 $70 \%$ 이상으로 나타났다(KISA, 2012).

이처럼 가정은 물론, 사업장에서 업무를 수행하기 위해 컴 퓨터를 이용하는 비율과 인터넷을 이용하는 비율이 점점 높 아지면서 장시간 컴퓨터에 노출되게 되는데, 장시간 $\mathrm{VDT}$ 워크스테이션(책상, 의자, 키보드/마우스, 모니터 등)에 노출 되는 경우 "VDT 증후군(거북목 증후군, 목 디스크, 수근관 증후군 등 상지부위 근골격계질환)"이라고 불리는 질환이 발 생할 수 있다. $\mathrm{VDT}$ 작업과 관련된 근골격계질환의 증상유발 에 관여하는 요인으로는 업무내용 및 작업조건 등과 관련된 직업요인과 개인적 특성 및 심리적인 요인 등이 복합적으로 작용하여 발병하는 것으로 알려져 있다(Shimai et al., 1986; Ong et al., 1987).

VDT 사무작업에 대한 위험성 평가는 주로 몸통이나 목의 굽힘동작을 중심으로 작업자세의 위험성을 평가하고 있으며, 특히 작업자세를 분석함에 있어 해부학적인 자세를 참조하 여 평가하고 있다. Karl and Anne(2001)은 저서 "Office Ergonomics"에서 인간공학적 워크스테이션 디자인의 중요 한 목적은 신체의 움직임을 염두에 두고 움직일 수 있는 공 간을 계획하여야 한다고 지적하였다. Straker et al. (2008) 및 Claus et al. (2009)은 앉은 자세에 대한 몸통 굽힘각도 의 기준점을 제시하였는데, 입고 있는 옷이나 머리카락 등 으로 몸통이나 목 부위의 굽힘 정도를 정확하게 인지할 수 없어 특별한 교육을 통해 작업을 분석한 사례도 있다. Kim and $\operatorname{Kim}(2011)$ 은 작업자세의 위험성을 평가하는 분석도구 별로 개별적인 굽힘각도 기준이 있음에도 불구하고 분석자 자신이 알고 있는 몸통과 목의 굽힘각도 기준을 모든 평가도 구에 적용하는 문제점에 대해 지적하였다.

무엇보다, Babski-Reeves et al.(2005)의 연구에서는
VDT 사무작업을 입력작업과 수식계산작업으로 구분함으로 써 VDT 워크스테이션을 설계하는데 활용할 것을 제안하였 고, ILO(1991)에서는 연속적인 VDT 사무작업을 두 종류 (자율성이 거의 없는 자료입력작업, 자율성이 많은 프로그램 작업)로 구분하여 휴식시간을 적정하게 배분하도록 권고하 고 있다. 또한, 일본의 노동위생관리에 포함된 $\mathrm{VDT}$ 작업관 리기준에는 사무작업의 종류(단순입력형, 구속형, 대화형, 기 술형, 감시형, 기타)에 따라 1 일 노출시간을 $\mathrm{A}$ 작업, $\mathrm{B}$ 작업, C작업으로 구분하여 제시하고 있다(JISHA, 2002). 우리나 라의 경우, 고용노동부 고시(2004-50호)에는 VDT 사무작 업을 구별 없이 동일하게 관리하도록 규정하고 있다.

따라서, 본 연구에서는 VDT 사무작업을 세 가지 유형으 로 구분하여, 해당 작업에 종사하는 사용자를 대상으로 현 장조사를 실시하여, 인간공학적인 평가도구인 RULA (Rapid Upper Limb Assessment, 1993) 와 ROSA (Rapid Office Strain Assessment, 2012)를 이용하여 VDT 사무작업유형 별 위험수준을 조사하고, 작업자세와 사무용 주변기기들을 사용함으로써 발생하는 문제점을 분석하고, 평가하는 것을 목적으로 하였다.

\section{Method}

다양한 유형의 VDT 사무작업에 대한 실태를 조사하고자 VDT 사무작업을 Table 1 과 같이 세 가지로 구분하였고, 해 당 작업내용을 포함하고 있는 7 개의 사업장을 대상으로 현 장조사를 실시하였다. 세 가지 VDT 사무작업유형은 콜센터 와 일반 서무작업에서 수행하는 자료검색 및 조회업무, 은행 및 병원 등에서 집중적으로 자료를 입력하는 자료입력업무, 마우스를 이용하여 장시간 도면 등을 그리는 설계업무로 구 분하였다. 이와 같은 사무작업유형별 주요 작업자세는 Table 2에 나타내었다.

Table 1. Work contents for the types of office work

\begin{tabular}{c|l}
\hline Types of office work & \multicolumn{1}{c}{ Work contents } \\
\hline Data search & $\begin{array}{l}\text { This work is to search and replace the } \\
\text { data, same as Call center, General Office } \\
\text { work and Program development work. }\end{array}$ \\
\hline Data entry & $\begin{array}{l}\text { This work is to enter the data intensive } \\
\text { using the keyboard, same as Bank, } \\
\text { Hospital and Accounting work. }\end{array}$ \\
\hline $\begin{array}{c}\text { Design work } \\
\text { (Drawings, etc.) }\end{array}$ & $\begin{array}{l}\text { This work is to draw the things using the } \\
\text { mouse, same as Design and Animation } \\
\text { work. }\end{array}$ \\
\hline
\end{tabular}


Table 2. The Majors working postures for the types of office work

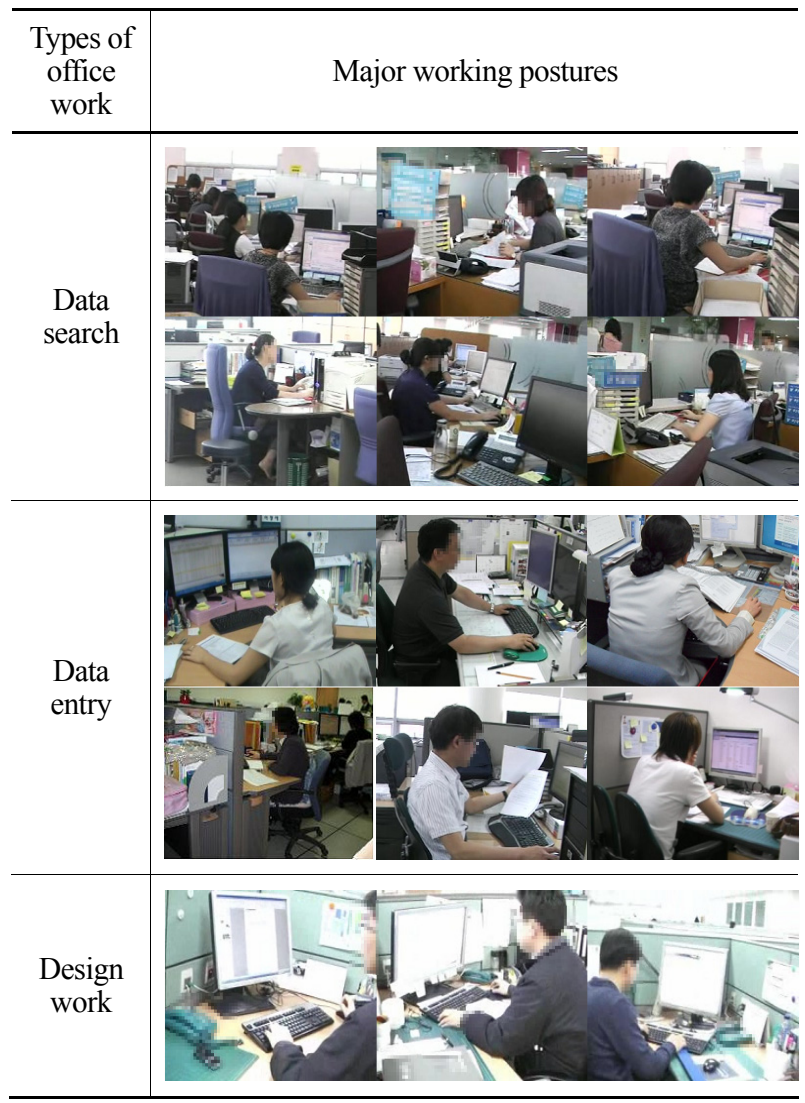

현장조사를 통해 세 가지 사무작업 유형별로 작업자세를 동영상으로 촬영하였는데, 각각의 사무작업의 유형에 해당하 는 작업내용을 포함하여 작업자당 약 5 20분씩 촬영하였다. 작업분석을 위해 촬영된 동영상에서 1 분에 3 장의 정지영상 을 추출하였는데, 자료검색 및 조회업무는 900개, 자료입력 업무는 420개, 설계업무는 480개로 총 1,800 개를 얻었다. 추출된 정지영상의 작업자세에 대해 RULA 및 ROSA를 이 용하여 작업의 위험수준을 분석하였다.

RULA는 조립, 정비, 육류가공, 치과, VDT 사무작업 등과 같이 주로 상지를 사용하는 작업의 부하를 전문적으로 분석 하기 위해 개발되었으며, 특히, 윗팔과 아랫팔, 손목은 물론, 목과 몸통에 대한 작업부하를 평가할 수 있다(McAtamney and Corlett, 1993). RULA는 상지의 좋지 않은 작업자세의 비율이 어느 정도인지를 파악할 수 있고, 정적 또는 반복적 인 작업여부, 작업을 수행하는데 필요한 힘의 크기 등 작업 으로 인한 근육부하를 평가할 수 있다. 분석결과는 총괄적인 작업자세 점수를 1 7점으로 나누고, 이 점수를 기준으로 4단계의 조치수준으로 위험수준을 구분하여 평가하고 있다.

그렇지만, 사무작업은 의자, 모니터, 키보드 및 마우스와
같은 주변기기를 어떻게 배치 또는 사용하느냐에 따라 작업 자세에 상당한 영향을 미침에도 불구하고, 그 동안 이들에 대한 평가는 부족하였다. 최근 Sonne et al.(2012)는 이러한 사무용 주변기기를 포함한 종합적인 평가가 가능한 ROSA 평가도구를 개발하였다. ROSA는 캐나다의 기술표준인 CSA Z412 (Guidelines for office ergonomics) 를 기준으로 하며, 이는 EN ISO 9241에 기초하고 있으며, 우리나라도 KS A ISO 9241를 통해 동일하게 적용되고 있다. ISO 9241에서는 $\mathrm{VDT}$ 를 이용하여 사무작업을 수행할 때, 인간공학적인 요건 들을 정의하고 있는데, VDT 사용자, 주변기기, 사무환경, 그 리고 $\mathrm{VDT}$ 작업이 조직되고 관리되는 수행방식을 포함하고 있다. ROSA는 이러한 ISO 9241의 항목을 중심으로 VDT 사무작업을 평가할 수 있도록 개발되었다. ROSA는 의자, 모 니터, 키보드 및 마우스를 사용할 때 취하게 되는 작업자세 를 관찰하여, 그 자세의 위험을 점수화하여 최종 위험수준을 결정하게 되는데, 위험수준이 5 이상이면 매우 위험한 것으 로 판단하여, 즉시 개선토록 권고하고 있다.

$\mathrm{ROSA}$ 의 사용절차는 다음과 같다. 사무작업 시 의자를 사 용하는 작업자세에 대해 의자의 좌면 높이와 깊이, 팔걸이 (어깨 자세), 등받이(몸통 자세)를 중심으로 취해지는 자세 의 위험성을 의자점수로 산정하고, 모니터(목 자세), 전화기 (목 자세), 마우스와 키보드(손목 자세) 등과 같이 컴퓨터 주변장치에 대한 사용시 자세와 노출시간을 고려하여 모니 터와 주변기기 점수를 산정한다. 산정된 의자점수와 모니터 와 주변기기 점수를 종합하여 최종점수를 산정하여 위험수 준을 평가하고 있다.

이와 같이, RULA는 상지와 목, 몸통 등의 신체부위별 작 업자세를 위주로 위험수준을 평가하는 반면에, ROSA는 의 자, 모니터와 주변기기 등을 사용할 때 취하는 작업자세는 물론, 노출시간 등과 같은 다양한 항목에 대해 종합적으로 평가할 수 있는 장점이 있다. 다만, ROSA의 경우, Sonne and Andrews (2012)의 연구를 통해 타당성이 검증되기는 하였으나, 아직까지 다양한 적용사례가 없어 신뢰성 검정 절 차가 남아 있는 것으로 보여진다.

\section{Results}

\subsection{RULA(Rapid Upper Limb Assessment)}

VDT 사무작업유형별 RULA 분석결과는 Table 3에 나 타내었다. 자료검색 및 조회업무의 RULA 점수는 2 4점 (위험수준 1 또는 2)으로 나타났고, 자료입력업무의 점수는 2 3점 (위험수준 1 또는 2)으로 나타나, 두 업무 모두 위 험수준이 높지 않은 것으로 평가되었다. 다만, 설계업무의 
RULA 점수는 3 5점 (위험수준 2 또는 3)으로써, 앞의 두 업무보다 위험수준이 높아 개선이 필요한 것으로 평가되었 다. 세 가지 사무작업유형에 대한 RULA 분석한 결과, 작업 자세의 위험수준과 유해요인에는 큰 차이는 없었으나 설계 업무의 경우에는 특정 신체부위의 과도한 굽힘과 장시간 정 적인 자세를 취하는 유해요인으로 인해 위험수준이 부가된 것으로 조사되었다.

Table 3. Result of the evaluation for the RULA checklist

\begin{tabular}{c|c|c|c}
\hline $\begin{array}{c}\text { Types of } \\
\text { office work }\end{array}$ & $\begin{array}{c}\text { Number of } \\
\text { still images }\end{array}$ & $\begin{array}{c}\text { RULA } \\
\text { scores }\end{array}$ & Action level $^{*}$ \\
\hline Data search & 900 & $2 \sim 4$ & 1,2 \\
\hline Data entry & 420 & $2 \sim 3$ & 1,2 \\
\hline Design work & 480 & $3 \sim 5$ & $\begin{array}{c}2,3 \\
\text { (Required Change) }\end{array}$ \\
\hline
\end{tabular}

* Action level

$1=$ Acceptable, $2=$ investigate further, $3=$ investigate further and change soon, $4=$ investigate and change immediately

사무작업유형별 유해요인을 살펴보기 위해, RULA 분석결 과에서 각 신체부위별로 최대점수가 $50 \%$ 이상 유해요인을 사무작업유형별로 추가 조사하였다(Table 4). 자료검색 및 조회업무는 아래팔을 책상높이까지 들어올린 상태에서 키보 드 작업을 수행하기 위해 팔을 모으는 동작, 전화를 받는 동 안 목의 굽힘과 젖힘동작이 발생하고 있었다. 자료입력업무 는 자료검색 및 조회업무와 별다른 차이는 없었으나, 키보드 를 통해 자료를 입력하는 동안 근육 사용이 높은 것이 유해 요인에 해당하였다. 설계업무는 장시간 정적으로 같은 자세 를 유지한 채 도면을 보는 작업에서 목의 과도한 굽힘동작과 연속적으로 같은 자세를 취하는 것이 유해요인으로 분석되 었다(Table 4).

Table 4. Risk factors through the RULA analysis

\begin{tabular}{c|l}
\hline $\begin{array}{c}\text { Types of } \\
\text { office work }\end{array}$ & \multicolumn{1}{c}{ Risk factors $^{*}$} \\
\hline Data search & $\begin{array}{l}\text { Lower arm is working across midline of the } \\
\text { body, Wrist twist, Neck is bending and twisted. }\end{array}$ \\
\hline Data entry & $\begin{array}{l}\text { Lower arm is working across midline of the } \\
\text { body, Wrist twist, Neck is bending. Posture } \\
\text { mainly static. }\end{array}$ \\
\hline Design work & $\begin{array}{l}\text { Lower arm is working across midline of the } \\
\text { body, Neck is bending and twisted, Posture } \\
\text { mainly static(prolonged working time) }\end{array}$ \\
\hline
\end{tabular}

* The maximum body part score is more than $50 \%$

\subsection{ROSA(Rapid Office Strain Assessment)}

RULA 분석 시 사용했던 동일한 정지영상을 이용하여 $\mathrm{ROSA}$ 를 통해 위험수준을 분석한 결과는 Table 5 에 나타내 었다. 자료검색 및 조회업무의 ROSA 점수는 평균 4.5점(범 위 3 6점)으로 개선이 필요 없는 것으로 조사되었다. 다만, 주변기기별 조사결과, 모니터/전화기 점수가 3 5점, 의자점 수가 2 7점, 마우스/키보드 점수가 2 3점으로, 다른 사무 작업에 비해 모니터나 전화기로 인한 위험이 높게 평가되었 다. 자료입력업무의 전체 위험수준은 평균 7.2점 (범위 5 8 점) 으로 높아 개선이 필요한 것으로 나타났는데, 이는 의자 점수가 4 7점으로 다른 사무작업보다 위험수준이 높게 나 타났고, 모니터/전화기 점수도 높은 수준이었다. 설계업무의 전체 위험수준은 평균 5.2점(범위 4 6점)으로 개선이 필요 한 것으로 조사되었는데, 마우스/키보드 점수가 3 4점으로 다른 사무작업에 비해 위험수준이 높게 나타났다.

Table 5. Result of the evaluation for the ROSA checklist

\begin{tabular}{c|c|c|c|c|c}
\hline \multirow{2}{*}{$\begin{array}{c}\text { Types of } \\
\text { office } \\
\text { work }\end{array}$} & $\begin{array}{c}\text { Number } \\
\text { of still } \\
\text { images }\end{array}$ & $\begin{array}{c}\text { Office } \\
\text { chair } \\
\text { score }\end{array}$ & $\begin{array}{c}\text { Monitor/ } \\
\text { Phone } \\
\text { score }\end{array}$ & $\begin{array}{c}\text { Keyboard } \\
\text { and mouse } \\
\text { score }\end{array}$ & $\begin{array}{c}\text { Grand ROSA } \\
\text { Score } \\
\text { (Mean) }\end{array}$ \\
\hline $\begin{array}{c}\text { Data } \\
\text { search }\end{array}$ & 900 & $2 \sim 7$ & $3 \sim 5$ & $2 \sim 3$ & $3 \sim 6(4.5)$ \\
\hline $\begin{array}{c}\text { Data } \\
\text { entry }\end{array}$ & 420 & $4 \sim 7$ & $4 \sim 5$ & $2 \sim 3$ & $\begin{array}{c}5 \sim 8(7.2) \\
\text { High risk }\end{array}$ \\
\hline $\begin{array}{c}\text { Design } \\
\text { work }\end{array}$ & 480 & $2 \sim 5$ & $3 \sim 5$ & $3 \sim 4$ & $\begin{array}{c}4 \sim 6(5.2) \\
\text { High risk }\end{array}$ \\
\hline
\end{tabular}

* The Score of greater than 5 are deemed to be 'high risk' and the office workstation should be assessed further.

$\mathrm{ROSA}$ 분석결과를 통해, 사무작업유형별로 주변기기에 대 한 유해요인을 살펴보았다. 의자에 대한 분석결과, 자료검색 및 조회업무, 자료입력업무는 주로 신장이 작은 여성들이 많 아 의자의 좌면 높이를 높게 사용하고 있으며, 이는 의자 사 용으로 인한 전체 위험수준을 높게 하였다. 특히, 신장이 작 은 여성의 경우에는 의자 좌면의 깊이도 의자점수를 높이는 데 영향을 주었다. 설계업무는 주로 남성들로써 의자에 대한 조건은 비교적 좋은 것으로 분석되었다.

모니터와 전화기 사용에 있어서, 자료검색 및 조회업무의 경우에는 모니터를 아주 다양한 위치에 배치해 사용하고 있 었다. 자료입력업무는 대부분 문서받침대를 비치하지 않고 있었고, 모니터를 측면에 배치함으로써 목을 $30^{\circ}$ 이상 비튼 상태에서 작업을 수행하였다. 설계업무의 모니터의 위치는 적정하게 배치되어 있으나 전화기는 멀리 떨어져 있고, 목과 
어깨를 이용해 받는 경우가 많았다. 사무작업유형에 상관없 이 모니터를 $75 \mathrm{~cm}$ 이상 멀리 떨어뜨려 놓은 상태에서 작업 하는 경우가 많았다.

마우스와 키보드는 전체적으로 점수가 높지 않았으나, 설 계업무의 경우에 도면 등을 그리는 정밀작업으로 인해 마우 스를 상당히 높은 위치에 두어 사용하고 있으며, 때때로 어 깨선에서 멀어지는 경우도 발생하였다.

또한, 사무작업유형별로 위험수준을 높이는 대표적인 유 해요인으로 노출시간을 들 수 있다. 자료검색 및 조회업무 는 노출시간이 30 분 1 시간 연속작업에 해당하거나 하루에 $1 \sim 4$ 시간 정도 작업하는 반면에, 자료입력 및 설계업무는 1 시간 이상 연속작업하거나 하루 4 시간이상 컴퓨터 작업을 하는 것으로 나타나 위험수준에 영향을 미치는 것으로 조사 되었다.

\section{Discussion and Conclusion}

최근 들어, 비제조업 특히 서비스업종에서 다양한 근골격 계질환이 발생하고 있는데, 특히 컴퓨터단말기를 사용하는 VDT 사무작업은 마우스와 키보드의 반복적인 사용으로 인 해 경견완증후군으로 알려진 $\mathrm{VDT}$ 증후군이 꾸준히 발생하 고 있다(Fahrbach and Chapman, 1990). 또한, 사무작업유 형에 있어 기존의 앉은 자세와 비교해 Sit-stand 형태의 $\mathrm{VDT}$ 작업이 근골격계질환의 호소율을 낮추고, 근육 활동량 이 현저하게 감소한다는 보고(Ebara et al., 2008; Choi, 2011)가 있듯이 사무작업의 형태가 다양하게 변화하고 있 는 것을 알 수 있다.

따라서, 본 연구에서는 세 가지 사무작업유형에 종사하는 작업자를 대상으로 VDT 사무작업에 대한 현장조사를 실시 하였다. 현장조사를 통해 얻어진 1,800 개의 정지영상을 이 용하여 RULA와 ROSA를 사용하여 유해요인을 분석하고 그 위험수준을 평가하였다. 이러한 분석을 통해 세 가지 사 무작업유형별 위험수준을 비교하였고, 기존의 작업자세 위 주의 평가와 사무용 주변기기를 포함한 평가결과를 비교하 여 제시하였다.

미국 내의 인간공학 전문가들을 대상으로 한 조사에서 가 장 많이 사용하는 평가도구로는 RULA $51.6 \%$, OWAS $21.4 \%$, REBA $17.9 \%$ 순으로 보고(Dempsey et al., 2005) 된 바와 같이, RULA는 전세계적으로 가장 빈번하게 사용되 는 대표적인 인간공학 평가도구로써, VDT 작업과 같은 상지 부위의 정적인 반복작업을 대상으로 작업의 위험수준을 평 가하는데 장점이 있다. 다만, 동적이면서 작업빈도가 높은 자세나 중량물 취급과 같은 작업부하가 높은 자세를 분석할
때에는 여러 작업장면들 중에서 대표값을 취하는 것이 추천 되고 있는데 (McAtamney and Corlett, 1993), 특히 작업장 면 중 가장 노출수준이 높은 최대값을 취하는 방법이 전문가 의 판단과 크게 다르지 않다(Park and Kwak, 2006)는 이 유로, 작업부하를 과대 평가하는 경향이 있다. 이러한 과대 평가에 대해, Kee and Park(2005)의 연구에서는 손목, 목과 몸통의 중립자세, 목 신전자세, 외부부하의 산입방법 등의 문제를 지적하였다. 그럼에도 불구하고, 근골격계질환을 예 방하는 측면에서는 부하를 저평가하는 것보다 엄격하게 평 가하는 것이 바람직하다고 고찰하였다. 또한, RULA가 작업 자세의 위험수준만 평가하다 보니, 유해요인을 상당히 포괄 적으로 제시하고 있어 구체적인 개선방안을 수립하는데 어 려움이 있다고 지적하였다(Sonne et al., 2012).

작업자세의 위험수준을 평가하는 RULA를 이용한 작업분 석결과, 설계업무는 일부 개선이 필요한 것으로 분석되었으 나, 세 가지 작업유형에 따른 유해요인과 위험수준에 큰 차 이를 발견할 수 없었다. 이것은 RULA가 사무작업과 같이 유사한 정적인 작업자세를 취하는 경우에 거의 같은 위험수 준으로 평가하는 것을 알 수 있었다. 또한, Sonne et al. (2012)의 지적과 같이, VDT 사무작업은 사무용 주변기기 를 어떻게 사용하느냐에 따라 유해요인을 명확하게 제시해 주어야 개선방안을 수립하는데 도움이 되는데, RULA는 그 역할을 제대로 수행하지 못하는 것을 알 수 있었다.

VDT 사무작업의 위험수준 평가는 작업자세뿐 아니라 사 용하고 있는 의자와 같은 사무용 주변기기에 대한 분석이 병행되어야 한다. OSHA (2013)에서는 VDT 사무작업에 대 한 유해요인 평가항목으로 작업자세는 물론, 사무용 주변기 기, 작업 절차와 작업환경을 고려하고 있으며, 작업자세에 큰 영향을 미치는 주변기기에 대한 구매 가이드라인도 제공 하고 있다. 이와 같이, 최근 연구들은 기존의 장시간 정적으 로 앉아 있는 상태의 사무작업형태뿐 아니라, 다양한 작업유 형과 사무용 주변기기의 사용과 관련된 부분을 유해요인조 사 시 고려하고 있다. 이는 다양한 사무기기의 형태와 위치 등에 따라 작업자세가 다양하게 변하기 때문에 VDT 사무작 업에 대한 정밀한 위험수준을 평가하기 위해서는 사무용 주 변기기에 대한 조사는 반드시 필요하다고 할 수 있다.

따라서, 본 연구에서는 작업자세뿐 아니라, 사무용 주변기 기(의자, 모니터/전화기, 마우스/키보드, 노출시간 등)의 사 용으로 인한 구체적인 유해요인까지 분석할 수 이는 ROSA 를 이용하여 분석하였다. 그 결과, 자료검색 및 조회업무는 평균 4.5점으로 개선이 필요 없는 것으로 평가되었으나, 자 료입력업무 7.2 점, 설계업무 5.2점으로 개선이 필요한 것으 로 나타났다. 구체적인 유해요인도 세 가지 사무작업유형에 따라 차이가 있는 것을 확인할 수 있었다. 자료검색 및 조회 작업은 모니터나 전화기의 위치로 인한 위험이 높은 것으로 
평가되었고, 집중적으로 자료를 입력하는 업무는 의자 사용 과 관련된 항목과 모니터/전화기로 인한 위험수준이 높게 나 타났다. 마지막으로 설계업무의 경우에는 마우스/키보드 사 용에 의한 위험수준이 다른 작업유형에 비해 높게 나타났다. 전체적인 위험수준을 기준으로 평가한 결과, 자료입력과 설 계업무에 대한 개선이 적극적으로 요구되는 것을 확인할 수 있었다.

이와 같이, $\mathrm{VDT}$ 사무작업유형에 따라 사무용 주변기기, 노출시간 등에 영향을 받는 유해요인에 차이가 있음이 확인 되었다. 따라서, '영상표시단말기(VDT) 취급근로자의 작업 관리지침(고용노동부 고시 제2004-50호)'에 세가지 사 무작업유형을 추가하는 등의 정책적 재검토가 요구된다.

\section{References}

Babski-Reeves, K., Stanfield, J. and Hughes, L., Assessment of video display workstation set up on risk factors associated with the development of low back and neck discomfort, International Journal of Industrial Ergonomics, 35, 593-604, 2005.

Claus, A.P., Hides, J.A., Moserley, G.L. and Hodges, P.W., Is 'ideal' sitting posture real?: Measurement of spinal curves in four sitting postures, Manual Therapy, 14, 404-408, 2009.

Dempsey, P.G., McGorry, R.W. and Maynard, W.S., A survey of tools and methods used by certificated professional ergonomists, Applied Ergonomics, 36, 489-503, 2005.

Dong-Shik Choi, Ergonomic Evaluation of Electrically Adjustable Table in VDU Work, Ergonomics Society of Korea Spring Conference, 2011.

Ebara, T., Kubo, T., Inoue, T., Murasaki, G., Takeyama, H., Sato, T., Susumura, H., Niwa, S., Takanishi, T., Tachi, N. and Itani, T., Effects of Adjustable Sit-stand VDT Workstations on Workers Musculoskeletal Discomfort, Alertness and Performance, Industrial Health, 46, 497 $-505,2008$.

Eruofound, European working conditions survey, http:// www.eurofound.europa.eu/surveys/smt/ewcs/results.htm, 2011.

Fahrbach, P. and Chapman, L., VDT work duration and Musculoskeletal Discomfort, AAOHN Journal, 28(1), 32-36, 1990.

International Labour Organization(ILO), VDT Safework, ILO-CIS, 1991.

Japan Industrial Safety and Health Association(JISHA), VDT作業におけ る労働衛生管理のためのガイドライン(Guidelines for Industrial Health Controls of VDT Operations), JISHA, 2002.

Karl, H.E., Kroemer, Anne D. Kroemer, Office Ergonomics, Taylor \& Francis Group, 2001.

Kee. D. and Park, K.H., Comparison of Posture Classification Schemes of OWAS, RULA and REBA, Journal of the KOSOS, 20(2), 127-132, 2005.

Kim, D.S. and Kim, C.H., A Study for the Appropriateness of the Different Reference Points in the Analysis of Working Posture, Journal of the Ergonomics Society of Korea, 30(5), 637-644, 2011.
Korea Internet Security Agency(KISA), 2012 Survey on the Internet Usage, KISA, 2012.

McAtamney, L. and Corlett, E.N., RULA: a survey method for the investigation of work-related upper limb disorders. Applied Ergonomics, 24, 91-99, 1993

National Information society Agency(NIA), 2012 Yearbook of Information Society Statistics, NIA, 2012.

Occupational Safety and Health Administration(OSHA), Computer Workstation's Home Page, http://www.osha.gov/SLTC/etools/ omputerworkstations/index.html, 2013.

Ong, C.N. and Phoon, W.O., Influence of age on VDT work, Acad. Med. Singapore, 16(1), 42-45, 1987.

Park, J.H. and Kwak, W.T., Comparison of the Representative Values of the Sampled Work Scenes with the Expert's Judgment in the MSD Workload Evaluation, Journal of the Ergonomics Society of Korea, 25(2), 205-210, 2006.

Shimai, S., Iwaski, S., et al. Survey on subjective symptoms in VDT works, Sangyo Igaku, 28, 87-97, 1986.

Sonne, M. and Andrews, D.M., The Rapid Office Strain Assessment (ROSA): Validity of online worker self-assessments and the relationship to worker discomfort, Occupational Ergonomics, 10(3), 83-101, 2012.

Sonne, M., Villalta, D.L. and Andrews, D.M., Development and evaluation of an office ergonomic risk checklist: ROSA-Rapid Office Strain Assessment, Applied Ergonomics, 43(1), 98-108, 2012.

Straker, L., Burgess-Limerick, R., Pollock, C., Murray, K., Netto, K., Coleman, J. and Skoss, R., The impact of computer display height and desk design on $3 \mathrm{D}$ posture during information technology work by young adults, J Electromyogr Kinesiol, 18, 336-349, 2008.

U.S. Census Bureau, Computer and internet use in the United States, http://www.census.gov/hhes/computer/publications/index.html, 2011.

\section{Author listings}

Day Sung Kim: ergoman@kosha.net

Highest degree: $\mathrm{PhD}$, Department of Industrial \& Management Engineering, University of Incheon

Position title: Researcher, Occupational Safety \& Health Research Institute, KOSHA

Areas of interest: Industrial Ergonomics, Musculoskeletal Disorders

Date Received : 2013-05-28

Date Revised :2013-08-28

Date Accepted : 2013-09-03 